\title{
A generalized set of correlations for plus fraction characterization
}

\author{
JAMIALAHMADI Mohamad ${ }^{1}$, ZANGENEH Hossein ${ }^{2 *}$ and HOSSEINI \\ Seyed Sajad ${ }^{2}$ \\ ${ }^{1}$ Petroleum Engineering Department, Petroleum University of Technology, Ahwaz, P. O. Box 63431, Iran \\ ${ }^{2}$ Chemical \& Petroleum Engineering Department, Sharif University of Technology, Tehran, P. O. Box 111559363, Iran \\ (C) China University of Petroleum (Beijing) and Springer-Verlag Berlin Heidelberg 2012
}

\begin{abstract}
The importance of accurate determination of the critical properties of plus fractions in prediction of phase behaviour of hydrocarbon mixtures by equations of state is well known in the petroleum industry. It has been stated in various papers (Elsharkawy, 2001) that using the plus fraction as a single group in equation of state calculations reduces the accuracy of the results. However in this work it has been shown that using the proper values of critical temperature and pressure for the plus fraction group can estimate the properties of hydrocarbon mixtures, and they are accurate enough to be used in reservoir engineering and enhanced oil recovery calculations.

In this paper, a new method is proposed for calculating the critical properties of plus fractions of petroleum fluids. One can use this method either in predicting critical pressure and temperature of single carbon numbers (SCNs) after the splitting process or in predicting critical pressure and temperature of the plus fraction as a single group. A comparison study is performed against Riazi-Daubert correlation (Riazi and Daubert, 1987) and Sancet correlations (Sancet, 2007) for 25 oil samples taken from 14 fields from southwest Iran. The results indicate the superiority of the proposed method to the Riazi-Daubert and Sancet correlations.
\end{abstract}

Key words: Plus fraction, critical properties correlation, single carbon number, bubble point calculations

\section{Introduction}

The importance of accurate determination of the critical properties of plus fractions in prediction of phase behaviour of hydrocarbon mixtures by equations of state is well known in the petroleum industry.

The plus fraction, usually $\mathrm{C}_{7+}$, contains thousands of hydrocarbon components heavier than SCN6. PVT analysis performed in laboratories usually provides a few data for the plus fraction, namely mole percent, molecular weight, and specific gravity. Physical properties and phase behaviour of a reservoir hydrocarbon sample are greatly influenced by small changes in properties of the sample's plus fraction. Therefore, for black and heavy oils, proper characterization of plus fractions is crucially important.

Using complex splitting and lumping processes, most authors have sacrificed simplicity and straightforwardness to achieve a high accuracy in prediction of petroleum fluids properties by equations of state. Splitting consists of dividing the plus fraction into single carbon numbers $(\mathrm{SCN})$ and then investigating the mole fraction and physical properties of each SCN group. Lumping is the process of merging

*Corresponding author. email: zangeneh@che.sharif.edu

Received September 11, 2011
SCNs to obtain a smaller number of components to use in equations of state calculations for reservoir fluids. In recent decades several authors have proposed new splitting methods (Pedersen et al, 1992), (Katz, 1983) and (Lohrenz et al, 1964), but most studies have aimed to improve the three parameter gamma distribution (TPG) based method proposed by Whitson (1983). All these methods need correlations that are able to predict physical properties of SCNs. As will be shown in this paper, accuracy of these correlations is a major factor in prediction of properties, which are used in equations of state calculations.

Danesh (1998) has listed the most widely used or promising methods for predicting critical properties of SCNs and the plus fraction of reservoir fluids. Lee-Kesler correlation (Kesler and Lee, 1976), Twu correlation (Twu, 1984) and Riazi-Daubert correlation (Riazi and Daubert, 1987) are some of these correlations. Recently, Sancet (2007) proposed a new method for calculating plus fraction, which is claimed to provide better results than Riazi-Daubert correlation. Methods proposed by Riazi and Daubert (1987) and Sancet (2007) will be discussed in the next sections.

In this study, a new set of correlations for calculation of critical properties of the plus fraction and SCNs, i.e. Tc, Pc and boiling temperature, was developed. Compared to the Riazi-Daubert correlation, Sancet correlation and other 
correlations, the proposed method is able to predict critical properties that lead to more accurate results in equations of state calculations, i.e. more accurate reservoir fluid bubble point pressure and density.

\section{Available correlations}

\section{1 Riazi-Daubert correlation}

Riazi and Daubert (1987) proposed a simple correlation for prediction of physical properties of hydrocarbon mixtures.

$$
\theta=a\left[\exp \left(b \theta_{1}+c \theta_{2}+d \theta_{1} \theta_{2}\right)\right] \theta_{1}^{e} \theta_{2}^{f}
$$

In this equation $\theta$ represents the property to be determined, $T_{\mathrm{c}}$ and $P_{\mathrm{c}}$ in this study, and $\theta_{1}$ and $\theta_{2}$ can be any two parameters characterizing molecular forces and molecular sizes of a component (Danesh, 1998). Pairs of components; boiling temperature $\left(T_{\mathrm{b}}\right)$ and molecular weight (MW) or molecular weight and specific gravity $(\mathrm{S})$ can be used in place of $\theta_{1}$ and $\theta_{2}$. Table 1 shows the constants used for RiaziDaubert correlation when all properties are in SI units.

Table 1 Constants used in Eq. (1)

\begin{tabular}{ccccccccc}
\hline$\theta$ & $\theta_{1}$ & $\theta_{2}$ & $a$ & $b$ & $c$ & $d$ & $e$ & $f$ \\
$T_{\mathrm{c}}$ & $T_{\mathrm{b}}$ & $\mathrm{S}$ & 9.5233 & $-9.3140 \times 10^{-4}$ & -0.54444 & $6.4791 \times 10^{-4}$ & 0.81067 & 0.53691 \\
$T_{\mathrm{c}}$ & $\mathrm{MW}$ & $\mathrm{S}$ & $3.0800 \times 10^{2}$ & $-1.3478 \times 10^{-4}$ & -0.61641 & 0.0000 & 0.2998 & 1.0555 \\
$P_{\mathrm{c}}$ & $T_{\mathrm{b}}$ & $\mathrm{S}$ & $3.1958 \times 10^{4}$ & $-8.5050 \times 10^{-3}$ & -4.8014 & $5.7490 \times 10^{-3}$ & -0.4844 & 4.0846 \\
$P_{\mathrm{c}}$ & $\mathrm{MW}$ & $\mathrm{S}$ & $3.1166 \times 10^{2}$ & $-1.8078 \times 10^{-3}$ & -0.3048 & 0.0000 & -0.8063 & 1.6015 \\
$T_{\mathrm{b}}$ & $\mathrm{MW}$ & $\mathrm{S}$ & 3.7659 & $3.7741 \times 10^{-3}$ & 2.98404 & $-4.2529 \times 10^{-3}$ & 0.40167 & -1.5826 \\
\hline
\end{tabular}

\section{2 Sancet correlation}

Sancet used the data set provided by Reid (Reid et al, 1987) to establish a relationship between MW and the critical properties $T_{\mathrm{c}}\left({ }^{\circ} \mathrm{R}\right)$ and $P_{\mathrm{c}}$ (psia).

$$
\begin{aligned}
& P_{\mathrm{c}}=82.82+653 \exp (-0.007427 M W) \\
& T_{\mathrm{c}}=-778.5+383.5 \ln (M W-4.075)
\end{aligned}
$$

To use the Edmister (1958) correlation for the acentric factor, Sancet developed a correlation for bubble point temperature $\left({ }^{\circ} \mathrm{R}\right)$.

$$
T_{\mathrm{b}}=194+0.001241\left(T_{\mathrm{c}}\right)^{1.869}
$$

Sancet compared both his and Riazi-Daubert's correlation results with 20 PVT laboratory test results performed using black oil samples from Argentinian fields. He concluded that using his correlation will slightly increase the accuracy of bubble point calculations over Riazi-Daubert's correlation. However, his correlation results in far better density prediction than Riazi-Daubert Correlation.

\section{3 Lee-Kesler acentric factor correlation}

Lee-Kesler acentric factor correlation (Kesler and Lee, 1976) is simply a re-arrangement of the Lee-Kesler vapor pressure correlation (Lee and Kesler, 1980).

For $T_{\mathrm{br}} \leq 0.8$

$$
\omega=\frac{\left(\ln P_{\mathrm{br}}-\frac{5.92714}{T_{\mathrm{br}}}+1.28862 \ln T_{\mathrm{br}}-0.169347 T_{\mathrm{br}}^{6}\right)}{\left(15.2518-\frac{15.6875}{T_{\mathrm{br}}}-13.4721 \ln T_{\mathrm{br}}+0.43577 T_{\mathrm{br}}^{6}\right)}
$$

For $T_{\mathrm{br}} \leq 0.8$

$$
\begin{aligned}
\omega= & -7.904+0.1352 K_{\mathrm{w}}-0.007465 K_{\mathrm{w}}^{2}+8.359 T_{\mathrm{br}} \\
& +\left(1.408-0.01063 K_{\mathrm{w}}\right) / T_{\mathrm{br}}
\end{aligned}
$$

where,

$\omega$ is the acentric factor.

$$
\begin{gathered}
P_{\mathrm{br}}=\frac{P_{\mathrm{b}}}{P_{\mathrm{c}}} \\
T_{\mathrm{br}}=\frac{T_{\mathrm{b}}}{T_{\mathrm{c}}}
\end{gathered}
$$

$P_{\mathrm{b}}$ is the pressure at bubble point temperature $\left(T_{\mathrm{b}}\right)$

$K_{\mathrm{w}}$ is the Watson characterization factor.

\section{The proposed model}

Many methods for molar distribution and physical properties characterization of petroleum fractions have been reported in literature (Pedersen et al, 1992) and (Katz, 1983). All these methods use a set of correlations for predicting critical properties of SCN and plus fraction groups. This study is aimed to develop such correlations, namely critical temperature, critical pressure, and bubble point temperature correlations. For the acentric factor, the correlation developed by Kesler and Lee is used.

Using the critical properties calculated with the LeeKesler correlations (see Table 2), and the average molecular weight of single carbon number groups SCN7 to SCN45, a relationship was established for calculation of critical temperature and pressure of SCN and plus fraction groups. A nonlinear least squares method was used to fit various nonlinear equations on the available data. It was found that for the plus fraction, the best models to fit the critical pressure, critical temperature and bubble point temperature 
Table 2 Critical properties calculated by Lee-Kesler Correlations

\begin{tabular}{|c|c|c|c|c|}
\hline $\mathrm{SCN}$ & $\mathrm{MW}, \mathrm{g} / \mathrm{mol}$ & $P_{\mathrm{c}}, \mathrm{atm}$ & $T_{\mathrm{c}}, \mathrm{K}$ & $T_{\mathrm{b}}, \mathrm{K}$ \\
\hline $\mathrm{C}_{7}$ & 96 & 30.97 & 543.20 & 366 \\
\hline $\mathrm{C}_{8}$ & 107 & 29.12 & 570.50 & 390 \\
\hline $\mathrm{C}_{9}$ & 121 & 26.94 & 598.50 & 416 \\
\hline $\mathrm{C}_{10}$ & 134 & 25.01 & 622.10 & 439 \\
\hline $\mathrm{C}_{11}$ & 147 & 23.17 & 643.60 & 461 \\
\hline $\mathrm{C}_{12}$ & 161 & 21.63 & 663.90 & 482 \\
\hline $\mathrm{C}_{13}$ & 175 & 20.43 & 682.40 & 501 \\
\hline $\mathrm{C}_{14}$ & 190 & 19.33 & 700.70 & 520 \\
\hline $\mathrm{C}_{15}$ & 206 & 18.25 & 718.60 & 539 \\
\hline $\mathrm{C}_{16}$ & 222 & 17.15 & 734.50 & 557 \\
\hline $\mathrm{C}_{17}$ & 237 & 16.35 & 749.20 & 573 \\
\hline $\mathrm{C}_{18}$ & 251 & 15.65 & 760.50 & 586 \\
\hline $\mathrm{C}_{19}$ & 263 & 15.06 & 771.00 & 598 \\
\hline $\mathrm{C}_{20}$ & 275 & 14.36 & 782.90 & 612 \\
\hline $\mathrm{C}_{21}$ & 291 & 13.83 & 793.30 & 624 \\
\hline $\mathrm{C}_{22}$ & 300 & 13.26 & 804.40 & 637 \\
\hline $\mathrm{C}_{23}$ & 312 & 12.83 & 814.00 & 648 \\
\hline $\mathrm{C}_{24}$ & 324 & 12.38 & 823.20 & 659 \\
\hline $\mathrm{C}_{25}$ & 337 & 11.84 & 832.70 & 671 \\
\hline $\mathrm{C}_{26}$ & 349 & 11.48 & 841.20 & 681 \\
\hline $\mathrm{C}_{27}$ & 360 & 11.13 & 849.60 & 691 \\
\hline $\mathrm{C}_{28}$ & 372 & 10.76 & 857.70 & 701 \\
\hline $\mathrm{C}_{29}$ & 382 & 10.49 & 864.30 & 709 \\
\hline $\mathrm{C}_{30}$ & 394 & 10.12 & 872.53 & 719 \\
\hline $\mathrm{C}_{31}$ & 404 & 9.88 & 880.00 & 728 \\
\hline $\mathrm{C}_{32}$ & 415 & 9.59 & 887.30 & 737 \\
\hline $\mathrm{C}_{33}$ & 426 & 9.36 & 893.90 & 745 \\
\hline $\mathrm{C}_{34}$ & 437 & 9.09 & 900.00 & 753 \\
\hline $\mathrm{C}_{35}$ & 445 & 8.91 & 905.90 & 760 \\
\hline $\mathrm{C}_{36}$ & 456 & 8.66 & 912.10 & 768 \\
\hline $\mathrm{C}_{37}$ & 464 & 8.53 & 917.30 & 774 \\
\hline $\mathrm{C}_{38}$ & 475 & 8.29 & 923.40 & 782 \\
\hline $\mathrm{C}_{39}$ & 484 & 8.13 & 928.20 & 788 \\
\hline $\mathrm{C}_{40}$ & 495 & 7.90 & 934.30 & 796 \\
\hline $\mathrm{C}_{41}$ & 502 & 7.78 & 938.50 & 801 \\
\hline $\mathrm{C}_{42}$ & 512 & 7.60 & 942.80 & 807 \\
\hline $\mathrm{C}_{43}$ & 521 & 7.46 & 947.60 & 813 \\
\hline $\mathrm{C}_{44}$ & 531 & 7.25 & 953.70 & 821 \\
\hline $\mathrm{C}_{45}$ & 539 & 7.14 & 957.80 & 826 \\
\hline
\end{tabular}

data, provided by Lee-Kesler correlations, are exponential, logarithmic, and polynomial functions, respectively. Coefficients of these functions were determined through nonlinear least squares calculations as described in the appendix.

The obtained correlations (Eqs. 7 and 8) can be used in cases where critical properties of single carbon numbers are needed. But more importantly this set of correlations can be used for calculating critical temperature and pressure of plus fractions. In this case splitting the plus fraction to single carbon number groups is unnecessary and, as will be shown in the next section, values of bubble point pressure calculated with this method are satisfactory, even without tuning.

Note that the proposed correlations, which are as simple as Riazi-Daubert correlation, use atmospheres as the pressure unit and degrees kelvin as the temperature unit.

$$
P_{\mathrm{c}}=36.02 \exp (-0.01323 M W)+26.12 \exp (-0.002561 M W)
$$

$$
T_{\mathrm{c}}=239.4 \ln (M W)-555.3
$$

Moreover, a boiling point temperature correlation has been derived from the same source as the critical properties source and is used to calculate the boiling point temperature of plus fractions to be employed in Edmister and Lee-Kesler acentric factor correlations.

$$
T_{\mathrm{b}}=0.0004989 T_{\mathrm{c}}^{2}+0.3639 T_{\mathrm{c}}+20.92
$$

\section{PVT data}

Twenty-five oil samples, all of which were black and volatile oils from 14 oil fields located in southwest Iran, were used in this study. PVT studies show that the API of the 25 oil samples ranges between 19.85 and 42.80 , and gas/oil ratio (GOR) ranges between 339 and $1980 \mathrm{SCF} / \mathrm{STB}$.

The composition of all the samples was analyzed and mole percent of 17 components was measured. These 17 components are hydrogen sulfide, carbon dioxide, nitrogen, methane, ethane, propane, i-butane, n-butane, i-pentane, n-pentane, SCN6, SCN7, SCN8, SCN9, SCN10, SCN11, and $\mathrm{C}_{12+}$. Most studies in literature consider the plus fraction as SCN7 and heavier components. In this study, however, we assumed that plus fraction is SCN12 and heavier components. Therefore, it is expected that better understanding of the composition of samples provides us with more accurate predictions of bubble point pressure and density of reservoir fluids. The PVT properties of the 25 samples are given in Table 3.

\section{Results and comparison with available correlations}

The critical temperature and pressure of the plus fractions of the 25 reservoir fluid samples were calculated by the Riazi-Daubert and Sancet correlations and also the proposed correlation in this paper. The Riazi-Daubert correlation is selected because it is one of the most widely used correlations in the industry and literature, while the Sancet correlation 
Table 3 PVT properties of samples

\begin{tabular}{|c|c|c|c|c|c|}
\hline Sample & $P_{\mathrm{b}}, \mathrm{psia}$ & API & $T_{\text {res }},{ }^{\circ} \mathrm{F}$ & $\begin{array}{c}\text { GOR, } \\
\text { SCF/STB }\end{array}$ & $\begin{array}{c}\mathrm{C}_{12+} \text { Content } \\
\mathrm{mol} \%\end{array}$ \\
\hline 1 & 2387 & 32.93 & 150 & 680.55 & 18.18 \\
\hline 2 & 3088 & 32.60 & 154 & 948.25 & 18.94 \\
\hline 3 & 1731 & 32.32 & 181 & 459.21 & 33.28 \\
\hline 4 & 2400 & 31.51 & 150 & 699.17 & 20.17 \\
\hline 5 & 2400 & 31.79 & 150 & 710.78 & 20.29 \\
\hline 6 & 4256 & 35.10 & 250 & 1397.86 & 15.75 \\
\hline 7 & 2877 & 29.72 & 190 & 732.18 & 23.13 \\
\hline 8 & 2696 & 30.26 & 190 & 760.06 & 21.94 \\
\hline 9 & 1845 & 27.47 & 255 & 547.00 & 30.67 \\
\hline 10 & 2025 & 28.97 & 170 & 517.81 & 25.56 \\
\hline 11 & 2009 & 28.54 & 170 & 510.91 & 28.06 \\
\hline 12 & 2681 & 26.99 & 185 & 601.00 & 23.67 \\
\hline 13 & 2152 & 28.23 & 165 & 515.00 & 24.15 \\
\hline 14 & 4024 & 32.24 & 215 & 1096.15 & 19.55 \\
\hline 15 & 3900 & 31.24 & 199 & 1046.55 & 19.11 \\
\hline 16 & 2291 & 30.22 & 160 & 581.00 & 22.48 \\
\hline 17 & 2880 & 23.60 & 200 & 599.12 & 30.21 \\
\hline 18 & 2178 & 30.05 & 160 & 565.00 & 24.76 \\
\hline 19 & 2671 & 26.99 & 185 & 608.00 & 24.86 \\
\hline 20 & 3950 & 31.28 & 250 & 1523.20 & 13.71 \\
\hline 21 & 1900 & 19.85 & 255 & 467.00 & 32.27 \\
\hline 22 & 1379 & 19.96 & 222 & 339.37 & 39.61 \\
\hline 23 & 2650 & 42.80 & 145 & 1343.58 & 7.51 \\
\hline 24 & 6364 & 33.24 & 209 & 1980.76 & 12.46 \\
\hline 25 & 2311 & 24.35 & 260 & 437.14 & 21.66 \\
\hline
\end{tabular}

is rather new and as claimed by the author it provides better physical properties.

Using plus fraction critical properties calculated by the three set of correlations explained above; first, a comparative study of bubble point pressures was undertaken. Table 4 presents the values of bubble point pressure calculated by the three correlations explained above and Fig. 1 displays the relative error of bubble point pressure calculations of each sample. Note that, unless otherwise specified, in all the calculations Soave-Redlich-Kwong equation of state with two parameters, and without any kind of tuning, is used. Moreover, it was noted that calculating acentric factor values by Lee-Kesler correlation results in better matches of the experimental values of bubble point pressure. Table 5 shows the effect of Edmister and Lee-Kesler acentric factor correlations on bubble point prediction of samples 11 to 15 . Lee-Kesler correlation predicted values are more accurate for four of these five samples.

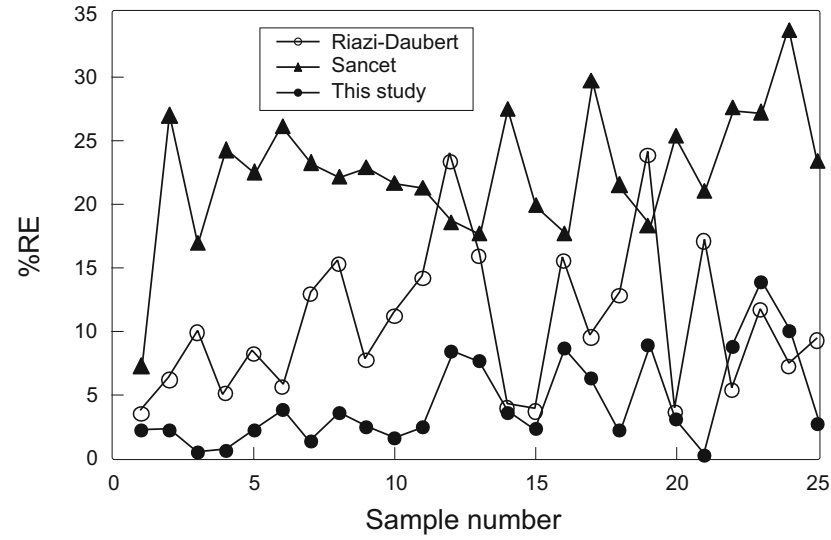

Fig. 1 Relative error of bubble point pressure calculations of each sample

Table 4 Values of bubble point pressure calculated by the three discussed methods and Soave-Redlich-Kwong equation of state

\begin{tabular}{|c|c|c|c|c|}
\hline Sample & $\begin{array}{c}P_{\mathrm{b}}, \text { psia } \\
\text { experimental }\end{array}$ & $\begin{array}{c}P_{\mathrm{b}}, \text { psia } \\
\text { Riazi-Daubert }\end{array}$ & $\begin{array}{l}P_{\mathrm{b}}, \text { psia } \\
\text { Sancet }\end{array}$ & $\begin{array}{c}P_{\mathrm{b}}, \text { psia } \\
\text { this study }\end{array}$ \\
\hline 1 & 2387 & 2469.36 & 2214.54 & 2439.42 \\
\hline 2 & 3088 & 3276.32 & 2255.38 & 3019.42 \\
\hline 3 & 1731 & 1901.42 & 1437.80 & 1723.12 \\
\hline 4 & 2400 & 2521.34 & 1818.82 & 2385.77 \\
\hline 5 & 2400 & 2595.45 & 1860.49 & 2452.39 \\
\hline 6 & 4256 & 4493.35 & 3142.18 & 4096.07 \\
\hline 7 & 2877 & 3246.20 & 2208.56 & 2913.85 \\
\hline 8 & 2969 & 3421.33 & 2311.79 & 3072.20 \\
\hline 9 & 1845 & 1985.61 & 1421.89 & 1800.82 \\
\hline 10 & 2025 & 2250.18 & 1586.20 & 2056.03 \\
\hline 11 & 2009 & 2292.54 & 1580.37 & 2056.79 \\
\hline 12 & 2681 & 3306.54 & 2182.51 & 2907.18 \\
\hline 13 & 2152 & 2492.93 & 1771.61 & 2316.33 \\
\hline 14 & 4024 & 4179.93 & 2917.32 & 3879.57 \\
\hline 15 & 3900 & 4041.10 & 3123.30 & 3810.20 \\
\hline 16 & 2275 & 2626.76 & 1871.77 & 2471.38 \\
\hline 17 & 2880 & 3152.15 & 2023.58 & 2697.80 \\
\hline 18 & 2190 & 2469.55 & 1718.98 & 2236.69 \\
\hline 19 & 2671 & 3306.54 & 2182.51 & 2907.18 \\
\hline 20 & 3950 & 4090.32 & 2948.17 & 3828.71 \\
\hline 21 & 1900 & 2223.40 & 1500.08 & 1903.91 \\
\hline 22 & 1379 & 1451.71 & 998.02 & 1258.16 \\
\hline 23 & 2650 & 2341.55 & 1929.44 & 2282.93 \\
\hline 24 & 6364 & 5907.13 & 4219.42 & 5725.60 \\
\hline 25 & 2311 & 2523.54 & 1770.05 & 2248.88 \\
\hline
\end{tabular}


Table 5 Values of bubble point pressure calculated by Lee-Kesler and Edmister acentric factor correlations and their respective relative error

\begin{tabular}{cccccc}
\hline Sample & $\begin{array}{c}P_{\mathrm{b}}, \mathrm{psia} \\
\text { experimental }\end{array}$ & $\begin{array}{c}P_{\mathrm{b}}, \mathrm{psia} \\
\text { Lee-Kesler Edmister }\end{array}$ & $\begin{array}{c}P_{\mathrm{b}}, \mathrm{psia} \\
\text { Lee-Kesler }\end{array}$ & $\begin{array}{c}\text { Relative error } \\
\text { Edmister }\end{array}$ & $\begin{array}{c}\text { Relative error } \\
\text { Edmin }\end{array}$ \\
\hline 11 & 2009 & 2056.79 & 1925.24 & $2.38 \%$ & $4.17 \%$ \\
12 & 2681 & 2907.18 & 2706.72 & $8.44 \%$ & $0.96 \%$ \\
13 & 2152 & 2316.33 & 2353.44 & $7.64 \%$ & $9.36 \%$ \\
14 & 4024 & 3879.57 & 3747.27 & $3.59 \%$ & $6.88 \%$ \\
15 & 3900 & 3810.20 & 3582.38 & $2.30 \%$ & $8.14 \%$ \\
\hline
\end{tabular}

Results show that values of bubble point pressure calculated using Sancet correlation are generally underestimated compared with the experimental value, with the average relative error of the 25 oil samples being $22.6 \%$, which is more than twice as high as that calculated using Riazi-Daubert correlation. Therefore, the Sancet correlation is not suitable for bubble point pressure calculations.

On the other hand, the Riazi-Daubert correlation tends to overestimate bubble point pressures and results in an average relative error of $10.4 \%$ for the 25 oil samples. The correlation proposed in this paper is superior to the other correlations used in the comparative study, with an average relative error of $4.4 \%$. Because the proposed set of correlations is based on typical values of critical temperature and pressure for single carbon number groups, it is expected that it retains its advantage over other correlations for oil samples extracted from reservoirs all around the world. The proposed set of correlations, however, becomes less accurate when GOR of reservoir fluid samples increases, i.e. for samples with a more volatile behaviour.

In addition to correlations, various equations of state also influence bubble point pressure calculations. In general using the two parameter Peng-Robinson equation of state results in a higher value of bubble point pressure than the SoaveRedlich-Kwong equation of state. Therefore, the RiaziDaubert correlation, which gives an overestimate of bubble point pressure, performs better with Soave-Redlich-Kwong equation of state. In contrast, Sancet's set of correlations provides better results when using Peng-Robinson equation of state. The proposed set of correlations, however, has no difference between the both equations of state and

Table 6 Values of bubble point pressure calculated by the three discussed correlations and Soave-Redlich-Kwong (SRK) and Peng-Robinson (PR) equations of state

\begin{tabular}{|c|c|c|c|c|c|c|c|}
\hline \multirow{2}{*}{ Sample } & \multirow{2}{*}{$\begin{array}{c}P_{\mathrm{b}} \text {, psia } \\
\text { experimental }\end{array}$} & \multicolumn{2}{|c|}{$\begin{array}{c}P_{\mathrm{b}} \text {, psia } \\
\text { Riazi-Daubert }\end{array}$} & \multicolumn{2}{|c|}{$\begin{array}{l}P_{\mathrm{b}} \text {, psia } \\
\text { Sancet }\end{array}$} & \multicolumn{2}{|c|}{$\begin{array}{l}P_{\mathrm{b}} \text {, psia } \\
\text { this study }\end{array}$} \\
\hline & & SRK & PR & SRK & PR & SRK & PR \\
\hline 1 & 2387 & 2469.36 & 2448.97 & 2214.54 & 2202.06 & 2439.42 & 2419.61 \\
\hline 2 & 3088 & 3276.32 & 3371.37 & 2255.38 & 2343.56 & 3019.42 & 3103.99 \\
\hline 3 & 1731 & 1901.42 & 1905.60 & 1437.80 & 1461.85 & 1723.12 & 1733.24 \\
\hline 4 & 2400 & 2521.34 & 2586.35 & 1818.82 & 1887.56 & 2385.77 & 2447.75 \\
\hline 5 & 2400 & 2595.45 & 2666.39 & 1860.49 & 1933.23 & 2452.39 & 2519.61 \\
\hline
\end{tabular}

outperforms both the Riazi-Daubert and Sancet correlations by a wide margin. Table 6 shows the influence of equations of state on bubble point pressure values of the first 5 samples calculated using the three correlations.

Fig. 2 shows the comparison between experimental and calculated values of bubble point pressure. Unlike the overestimated result of the Riazi-Daubert correlation and the underestimated result of the Sancet correlation, the proposed set of correlations doesn't always lead to overestimated or underestimated results. More importantly, the proposed correlations yield good estimation of bubble point pressures all over the study range of pressures.

To assess the performance of correlations in predicting gas and liquid density, differential liberation tests for the first

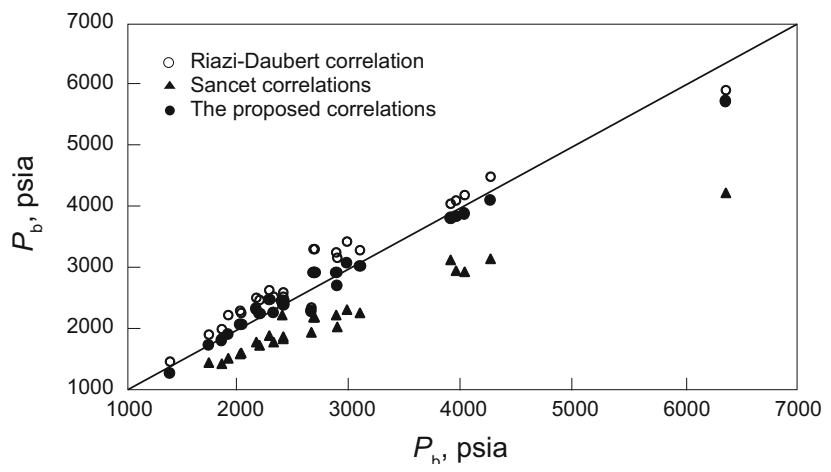

Fig. 2 Comparison of predicted bubble point pressures by the three correlations 
Table 7 Comparison of experimental values of liquid specific gravity with the ones obtained from Riazi-Daubert and the proposed correlations

\begin{tabular}{|c|c|c|c|c|}
\hline Sample number & Pressure step, psia & $\begin{array}{l}\text { Liquid specific gravity } \\
\text { experimental }\end{array}$ & $\begin{array}{l}\text { Liquid specific gravity } \\
\text { Riazi-Daubert }\end{array}$ & $\begin{array}{c}\text { Liquid specific gravity } \\
\text { this study }\end{array}$ \\
\hline \multirow{5}{*}{1} & 2024 & 0.7194 & 0.677844 & 0.681146 \\
\hline & 1622 & 0.7309 & 0.703848 & 0.709492 \\
\hline & 1222 & 0.7426 & 0.727512 & 0.735126 \\
\hline & 822 & 0.7551 & 0.750086 & 0.759519 \\
\hline & 422 & 0.7677 & 0.773349 & 0.784716 \\
\hline \multirow{5}{*}{2} & 2538 & 0.7111 & 0.691879 & 0.705054 \\
\hline & 2033 & 0.7258 & 0.697439 & 0.712089 \\
\hline & 1533 & 0.7430 & 0.703426 & 0.719559 \\
\hline & 1028 & 0.7587 & 0.709886 & 0.727530 \\
\hline & 526 & 0.7772 & 0.717073 & 0.736343 \\
\hline \multirow{5}{*}{3} & 1513 & 0.7396 & 0.708566 & 0.720846 \\
\hline & 1213 & 0.7474 & 0.713977 & 0.728240 \\
\hline & 913 & 0.7555 & 0.719525 & 0.735724 \\
\hline & 613 & 0.7639 & 0.725272 & 0.743394 \\
\hline & 313 & 0.7728 & 0.731516 & 0.751665 \\
\hline \multirow{5}{*}{4} & 2020 & 0.7186 & 0.694172 & 0.704095 \\
\hline & 1620 & 0.7309 & 0.699489 & 0.710485 \\
\hline & 1220 & 0.7421 & 0.705262 & 0.717348 \\
\hline & 820 & 0.7523 & 0.711484 & 0.724683 \\
\hline & 420 & 0.7655 & 0.718364 & 0.732750 \\
\hline \multirow{5}{*}{5} & 2041 & 0.7186 & 0.694452 & 0.704497 \\
\hline & 1641 & 0.7309 & 0.699659 & 0.710768 \\
\hline & 1241 & 0.7421 & 0.705327 & 0.717519 \\
\hline & 841 & 0.7523 & 0.711449 & 0.724748 \\
\hline & 441 & 0.7655 & 0.718217 & 0.732694 \\
\hline
\end{tabular}

five samples are simulated and compared with the differential liberation test performed in the laboratory. Tables 7 and 8 present the specific gravity values of liberated liquid and gas at each step and Tables 9 and 10 show the cumulative relative error of calculations performed for liquid and gas specific gravity, respectively. Except for the first sample, the cumulative error of gas specific gravity calculations by the proposed set of correlations in successive steps of differential liberation test is comparable to that by the Riazi-Daubert correlation. However, the cumulative error of liquid specific gravity calculations by the proposed set of correlations is much less than that by the Riazi-Daubert correlation. Note that in liquid specific gravity calculations, to achieve better

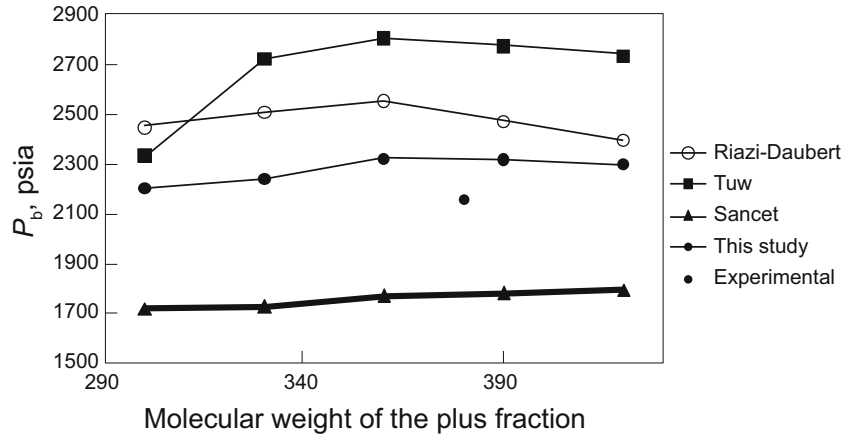

Fig. 3 Effect of molecular weight of $\mathrm{C}_{12+}$ on bubble point pressure calculations 
Table 8 Comparison of experimental values of gas specific gravity with the ones obtained from Riazi-Daubert and the proposed correlations

\begin{tabular}{|c|c|c|c|c|}
\hline Sample number & Pressure step, psia & $\begin{array}{c}\text { Gas specific gravity } \\
\text { experimental }\end{array}$ & $\begin{array}{l}\text { Gas specific gravity } \\
\text { Riazi-Daubert }\end{array}$ & $\begin{array}{c}\text { Gas specific gravity } \\
\text { this study }\end{array}$ \\
\hline & 2024 & 0.7070 & 0.457844 & 0.783441 \\
\hline & 1622 & 0.6952 & 0.483848 & 0.765648 \\
\hline \multirow[t]{5}{*}{1} & 1222 & 0.6974 & 0.507512 & 0.766040 \\
\hline & 822 & 0.7163 & 0.530086 & 0.792314 \\
\hline & 422 & 0.7834 & 0.553349 & 0.888038 \\
\hline & 2538 & 0.7275 & 0.724832 & 0.724113 \\
\hline & 2033 & 0.7090 & 0.717029 & 0.716701 \\
\hline \multirow[t]{5}{*}{2} & 1533 & 0.7072 & 0.719258 & 0.719129 \\
\hline & 1028 & 0.7146 & 0.739211 & 0.739201 \\
\hline & 526 & 0.7703 & 0.810150 & 0.810329 \\
\hline & 1513 & 0.7038 & 0.705904 & 0.704052 \\
\hline & 1213 & 0.7108 & 0.713739 & 0.711580 \\
\hline \multirow[t]{5}{*}{3} & 913 & 0.7259 & 0.730259 & 0.727727 \\
\hline & 613 & 0.7588 & 0.765397 & 0.762227 \\
\hline & 313 & 0.8460 & 0.858684 & 0.854121 \\
\hline & 2020 & 0.6860 & 0.715968 & 0.716361 \\
\hline & 1620 & 0.6808 & 0.706514 & 0.706974 \\
\hline \multirow[t]{5}{*}{4} & 1220 & 0.6847 & 0.707402 & 0.707840 \\
\hline & 820 & 0.7104 & 0.725649 & 0.726083 \\
\hline & 420 & 0.7737 & 0.793349 & 0.793983 \\
\hline & 2041 & 0.6860 & 0.717794 & 0.718167 \\
\hline & 1641 & 0.6808 & 0.708231 & 0.708674 \\
\hline \multirow[t]{3}{*}{5} & 1241 & 0.6847 & 0.708770 & 0.709190 \\
\hline & 841 & 0.7104 & 0.726031 & 0.726440 \\
\hline & 441 & 0.7737 & 0.789131 & 0.789703 \\
\hline
\end{tabular}

Table 9 Cumulative relative error of calculations for liquid specific gravity

\begin{tabular}{ccc}
\hline Sample number & $\begin{array}{c}\text { Liquid specific gravity } \\
\text { Riazi-Daubert }\end{array}$ & $\begin{array}{c}\text { Liquid specific gravity } \\
\text { this study }\end{array}$ \\
\hline 1 & 12.91 & 12.05 \\
2 & 26.11 & 15.26 \\
3 & 23.83 & 13.14 \\
4 & 24.24 & 16.10 \\
5 & 24.20 & 15.98 \\
\hline
\end{tabular}

Table 10 Cumulative relative error of calculations for gas specific gravity

\begin{tabular}{ccc}
\hline Sample number & $\begin{array}{c}\text { Gas specific gravity } \\
\text { Riazi-Daubert }\end{array}$ & $\begin{array}{c}\text { Gas specific gravity } \\
\text { this study }\end{array}$ \\
\hline 1 & 148.23 & 54.76 \\
2 & 11.82 & 11.88 \\
3 & 3.68 & 1.81 \\
4 & 16.15 & 16.48 \\
5 & 16.37 & 16.69 \\
\hline
\end{tabular}


results volume shift methods were used.

Fig. 3 displays the effect of molecular weight of the plus fraction on bubble point pressure calculations of sample 13 . Again, it is clear that the proposed set of correlations yield the best result. Moreover, it follows the same pattern for various molecular weights as other well-established correlations (Twu and Riazi-Daubert correlations) do.

\section{Conclusions}

Based on the results obtained in this study the following conclusions can be drawn:

1) This study presents a new set of correlations developed to calculate critical properties of plus fractions of reservoir fluids. Whether the plus fraction is $\mathrm{C}_{7+}$ (as in most cases discussed in literature) or a heavier pseudo-component $\left(\mathrm{C}_{12+}\right.$ in this study), the proposed critical pressure and temperature correlations yield the best matches of experimental bubble point pressure among other commonly used correlations .

2) The proposed set of correlations can be used in process of determining reservoir fluid saturation pressure or other physical properties (e.g. liquid and gas specific gravity). Assuming errors of $20 \%$ for bubble point pressure and density measurements, it is concluded that using the plus fraction as a single pseudo-component, instead of splitting it into more pseudo-components, yields satisfactory bubble point pressure and density values.

3) The results of performing bubble point pressure calculations using the proposed set of correlations combined with Soave-Redlich-Kwong and Peng-Robinson equations of state show that the choice of equation of state does not influence the performance of the proposed correlations.

\section{Conversion factors}

$$
\begin{aligned}
& 1 \mathrm{psia}=6.894757 \mathrm{E}+03 \mathrm{~Pa} \\
& 1 \mathrm{~atm}=1.01325 \mathrm{E}+05 \mathrm{~Pa} \\
& { }^{\circ} \mathrm{F}=1.8 \mathrm{~K}-459.67 \\
& { }^{\circ} \mathrm{R}=1.8 \mathrm{~K} \\
& 1 \mathrm{ft}^{3} / \mathrm{bbl}=0.180229443 \mathrm{~m}^{3} / \mathrm{m}^{3}
\end{aligned}
$$

\section{Nomenclatures}

$$
\begin{aligned}
& K_{\mathrm{w}}=\text { Watson characterization factor } \\
& \mathrm{MW}=\text { Molecular weight, } \mathrm{g} / \mathrm{mol} \\
& P_{\mathrm{b}}=\text { Boiling point pressure, psia } \\
& P_{\mathrm{br}}=\text { Reduced boiling point pressure, } \mathrm{psia} \\
& P_{\mathrm{c}}=\text { Critical pressure, atm } \\
& T_{\mathrm{b}}=\text { Boiling point temperature, } \mathrm{K} \\
& T_{\mathrm{br}}=\text { Reduced boiling point temperature, } \mathrm{K} \\
& T_{\mathrm{c}}=\text { Critical temperature, } \mathrm{K} \\
& S=\text { Specific gravity } \\
& \theta=T_{\mathrm{c}} \text { or } P_{\mathrm{c}}, \mathrm{K} \text { or atm } \\
& \theta_{1}=T_{\mathrm{b}} \text { or MW, } \mathrm{K} \text { or } \mathrm{g} / \mathrm{mol} \\
& \theta_{2}=\text { Specific gravity } \\
& \omega=\text { Acentric factor }
\end{aligned}
$$

\section{References}

Bates D M and Watts D G. Nonlinear Regression Analysis and Its Applications. The United States of America: John Wiley \& Sons.
1988. 39-42

Danesh A. PVT and Phase Behavior of Petroleum Reservoir Fluids. The Netherlands: Elsevier. 1998. 221-225

Edmister W C. Applied hydrocarbon thermodynamic, part 4: Compressibility factors and equations of State. Petroleum Refiner. 1958. 37: 173-179

Elsharkawy A M. Characterization of the Plus Fraction and Prediction of the Dewpoint Pressure for Gas Condensate Reservoirs. Paper SPE 68776 presented at the 2001 SPE Western Regional Meeting. March 26-30. 2001. Bakersfield. California. USA

Frandsen P E, Jonasson K, Nielsen H B, et al. Unconstrained Optimization. 3rd Edition. Denmark: IMM, DTU. 2004. 1-27

Katz D. Overview of phase behavior of oil and gas production. Journal of Petroleum Technology. June 1983: 1205-1214

Kesler M G and Lee B I. Improved prediction of enthalpy fractions. Hydrocarbon Processing. 1976. 55: 153-158

Lee B I and Kesler M G. Improved vapour pressure prediction. Hydrocarbon Processing. July 1980: 163-167

Lohrenz J, Bra B G and Clark C R. Calculating viscosities of reservoir fluids from their compositions. Journal of Petroleum Technology. 1964: 1171-1176

Madsen K, Nielsen H B and Tingleff O. Methods for Non-Linear Least Squares Problems. Denmark: IMM, DTU. 2004. 1-24

Pedersen K S, Bililie A L and Meisingset K K. PVT calculations on petroleum reservoir fluids using measured and estimated compositional data of the plus fraction. Industrial \& Engineering Chemistry Research. 1992. 31: 1378-1384

Reid R C, Prausnitz J M and Poling B E. The Properties of Gases and Liquids. New York: McGraw-Hill Companies. 4th edition. April 1987

Riazi M R and Daubert T E. Characterization parameters for petroleum fractions. Industrial \& Engineering Chemistry Research. 1987. 26: 755-759

Sancet G F. Heavy Fraction C7+ Characterization for PR-EOS. Paper SPE-113026-STU presented at the SPE International Student Paper Contest at the SPE Annual Technical Conference and Exhibition, November 11-14, 2007, Anaheim, California

Twu C H. An internally consistent correlation for predicting the critical properties and molecular weights of petroleums and coal-tar liquids. Fluid Phase Equilibria. 1984. 16: 137-150

Whitson C H. Characterizing hydrocarbon plus fractions. Society of Petroleum Engineers Journal. 1983. 23: 683-694

\section{Appendix}

Nonlinear least squares method was used to fit nonlinear equations on the available data. This appendix is a brief account of how this method can be used to obtain unknown parameters of the proposed critical pressure correlation (the same principle applies to the other proposed correlations).

Application of nonlinear least square method to fit nonlinear equations on critical pressure data provided by Lee and Kesler confirmed that the best model for these data is an exponential function. An exponential fitting model can be written as

$$
M(x, t)=x_{3} e^{x_{1} t}+x_{4} e^{x_{2} t}
$$

The model depends on the parameters $x=\left[x_{1}, x_{2}, x_{3}, x_{4}\right]^{T}$. We assume that there exists an $x^{\dagger}$ so that

$$
y_{i}=M\left(x^{\dagger}, t_{i}\right)+\varepsilon_{i}
$$


where the $\left\{\varepsilon_{i}\right\}$ are (measurement) errors on the data ordinates, assumed to behave like white noise (Madsen et al, 2004).

For any choice of $x$ we can compute the residuals

$$
\begin{aligned}
f_{i}(x) & =y_{i}-M\left(x, t_{i}\right) \\
& =y_{i}-x_{3} e^{x_{1} t_{i}}-x_{4} e^{x_{2} t_{i}}
\end{aligned}
$$$$
(i=1, \cdots, m)(\mathrm{A}-3)
$$

For least squares fit the parameters are determined as the minimizer $x^{*}$ of the sum of squared residuals. This is defined as a least squares problem: Find $x^{*}$, a local minimizer for

$$
F(x)=\frac{1}{2} \sum_{i=1}^{m}\left(\left(f_{i}(x)\right)\right)^{2}=\frac{1}{2}\|f(x)\|^{2}=\frac{1}{2} f(x)^{\mathrm{T}} f(x)
$$

where $f_{i}: R^{n} \mapsto R, i=1, \cdots, m$ are given functions, and $m \geq \mathrm{n}$.

Several methods can be used to solve this problem. An approach suggested by Gauss is to use a linear approximation to the expectation function, $f$, to iteratively improve an initial guess $x^{0}$ for $x$ and keep improving the estimates until there is no change. This approach is called the "Gauss-Newton" method. For small $\|h\|$ it is followed from the Taylor expansion that

$$
f(x+h) \approx \ell(h) \equiv f(x)+J(x) h
$$

where $J(x)$ is the Jacobian. Inserting this in the definition (A-4) of $F$ we see that

$$
\begin{aligned}
F(x+h) & \approx L(h) \equiv \frac{1}{2} \ell(h)^{T} \ell(h) \\
= & \frac{1}{2} f^{T} f+h^{T} J^{T} f+\frac{1}{2} h^{T} J^{T} J h \\
= & F(x)+h^{T} J^{T} f+\frac{1}{2} h^{T} J^{T} J h
\end{aligned}
$$

with $f=f(x)$ and $J=J(x)$. Further calculations show that $L(h)$ has a unique minimizer, which can be found by solving

$$
\left(J^{T} J\right) h_{g n}=-J^{T} f
$$

where $h_{g n}$ is the Gauss-Newton step. Using $h_{g n}$ as the descent direction in a descent method, e.g. the steepest descent method, the local minimizer for $F(x)$, and therefore unknown parameters of equation (A-1), can be found iteratively. For more information on various nonlinear least squares method and their performance see Frandsen et al (2004), Madsen et al (2004), and Bates and Watts (1988).

(Edited by Zhu Xiuqin) 